\title{
Olympus Imaging Fraud Scandal: A Case Study
}

Dennis Elam, Texas A\&M University-San Antonio, USA

Marion Madrigal, Texas A\&M University-San Antonio, USA

Maura Jackson, Texas A\&M University-San Antonio, USA

\begin{abstract}
This case examines the two decade long tobashi scheme by Olympus Imaging Executives to hide $\$ 1.7$ billion in losses. In the 1980s, a soaring yen and falling dollar caused bottom line income problems for many Japanese companies. Some companies sought to offset the declining revenue with zaiteku, a form of speculative investment. While early activities generated profits in 1987, by 1991 Olympus recorded 2.1 billion losses in yen. Rumors circulated that by the late 1990s, losses had grown larger. Rather than come clean and admit the losses, management continued to 'double down' with riskier investments. Olympus created a tobashi scheme to shift losses off the Olympus balance sheet.

Olympus created a tobashi scheme to shift losses off the Olympus balance sheet. Companies located in the Cayman Islands were purchased via exorbitant Management and Acquisition Fees. When the first Western President, Michael Woodford, questioned these practices, he was fired after two weeks on the job. Woodford became perhaps the first CEO ever to blow the whistle on his own firm. The subsequent scandal brought arrests of the executive team, an $80 \%$ decline in share price, the threat of de-listing on the Tokyo Exchange, and an international look at Japanese Corporate Governance. A detailed list of questions along with extensive teaching notes, bibliography, and references are provided. The case should be of interest in an accounting audit, ethics, governance, or international accounting class.
\end{abstract}

Keywords: Corporate Governance; Whistleblower; Fraud; Tobashi; Zaiteku; Derivatives; Confucian

\section{INTRODUCTION}

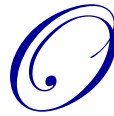

lympus hid the imaging scandal for nearly twenty years, dating back to the 1980s. Olympus is a Japanese company that produces cameras and medical imaging equipment. This case is unique since the whistle blower was Olympus' own president and CEO, Michael C. Woodford, hired in September of 2007. (Mintz, 2012) Now the former Board Chairman and 18 other past and present company officials are facing lawsuits and even charges from both British and Japanese officials. (Kubota, 2012)

\section{FACTS AND TIMELINE OF THE OLYMPUS SCANDAL}

In 1980, Toshiro Shimoyama was the president and CEO of Olympus Corporation. Olympus' operating income fell significantly because of the sharp appreciation of the yen. The CEO decided to develop an aggressive financial assets management unit within the Accounting Department headed by Hideo Yamada. This unit was to make speculative investments known as zaiteku. From these aggressive asset management activities, handsome profits were produced. In 1987, with Yamada in charge of the speculative investments deal, a man named Hisashi Mori became his subordinate in the investment dealings. In time, Yamada and Mori's dealings propelled them into upper management. Mori became an executive vice president and board director while Yamada became a standing corporate auditor. Ten years passed before the speculative investment activities resulted in substantial losses. Yamada and Mori's investment group doubled and tripled down by investing in high-risk, high-return products, and 
risky financial products that offered interest advancement as well as the riskier, complex structured bonds. (McKenna, 2012)

By the late 1990s, investment losses at Olympus had reached nearly \$100B yen. Yet Yamada and Mori continued to bet money in risky investments in a desperate bid to recover losses. These losses were masked through a Japanese accounting standard that allowed financial assets to be accounted for at historical cost basis versus writing them down to a lower market value. In 1997, the accounting laws were modified which forced Japan to adopt the fair value accounting system, or "market-to-market accounting," as part of its implementation of International Financial Reporting Standards. (Mintz, 2012) As accountants, Yamada and Mori knew they would soon be forced to reveal the fair value of the impaired assets they were holding.

In 1998, with President Shimoyama's knowledge and approval, Yamada and Mori came up with a "loss separation scheme" to work their way around the new market-to-market accounting laws. It would transfer the nearly worthless financial assets Olympus had acquired to entities whose accounts would not be consolidated back into Olympus' financial statements. These entities are referred to as "shell companies," which are off balance sheet companies. This scheme involved selling the assets to parties that would accept them at book value. It would be necessary to create dummy entities that Yamada and Mori could influence in order to continue to hide the losses. Olympus asked the President of Axes Japan Securities and the President of Axes America to set up these dummy entities.

The president of Axes Japan Securities and President of Axes America were asked by Olympus to set up these dummy entities. In 1998, the first "receiver fund," or dummy entity, called Central Forest and registered in the Cayman Islands, was set up to hide the losses. Yamada and Mori obtained financing from a bank in Liechtenstein. As collateral to obtain a loan to finance this dummy entity, Yamada and Mori deposited Olympus-owned Japanese government bonds valued at about 21 billion yen with the bank in return for 30 billion yen from them. Olympus' Asset Management also invested 35 billion yen in a class fund managed by this bank, which found its way into this dummy entity as well. Aside from borrowing from the bank in Liechtenstein, Yamada and Mori used a bank in Singapore to get another 45 billion yen into the dummy entity. After Central Forest was set up, Yamada and Mori began setting up the second dummy entity called Easterside Investments. Yamada and Mori invested another 60 billion yen into a different fund whose bond portfolio was lent to this dummy entity. (Bacani, 2011)

Up until 1998, Yamada and Mori succeeded in hiding these assets with a combined book value of 64 billion yen in Central Forest. Adding one last dummy entity, Yamada and Mori set up Quick Progress, having a book value of 32 billion yen. Yamada and Mori knew they needed to find a way to make the losses disappear, so they began to set up a loss disposition scheme. This involved the purchase of start-ups and entrepreneurial ventures at vastly inflated prices and payment of huge advisory fees for merger and acquisitions (M\&A) deals.

They used part of the money that flowed out of Olympus for these inflated purchases to retire the loan from the banks. Those banks financed the dummy enterprises and other obligations, and then would bring back the money that went into the investment funds.

They used part of the money that flowed out of Olympus for these inflated purchases to retire the loan from banks that financed the dummy enterprises and other obligations, and bring back the money that went into the investment funds. The high purchase prices of companies were accounted for as goodwill on Olympus' balance sheet. Yamada and Mori believed they were golden because the goodwill would be amortized over time down to zero. Then the money that Yamada and Mori lost on bad assets was transferred to the receiver funds, which could be properly accounted for without anyone's knowledge. (McKenna, 2012)

Years later, Olympus' external auditor, KPMG, did not agree with the vastly overvalued goodwill ascribed to the purchases. Olympus was forced to take an impairment charge of 55.7 billion yen in March of 2009 and another 1.3 billion yen in March of 2010. The company took a financial hit, but from Yamada and Mori's point of view, the impairment still allowed them to finally dispose of part of the investment losses they had hidden away in the receiver funds. 
Yamada and Mori then embarked on a scheme to acquire a company named Gyrus. The purpose of this transaction was to make another attempt to disguise the 62 billion yen represented by the money invested in the fund lent to Easterside as goodwill.

The purpose of this transaction was to make another attempt to disguise 62 billion yen represented by the money invested in the fund lent to Easterside as goodwill. With this transaction, Yamada and Mori believed they would finally be able to retire the last of their investment losses. Yamada and Mori had to somehow inflate the purchase price, to account for the purchase of Gyrus; so, the two men overpriced the advisory fees for this purchase. Acting as M\&A advisors, the presidents of Axes America and Japan negotiated a cash payment of US \$12 million of the grant of Gyrus warrants and preference shares that Olympus later bought back for US $\$ 670$ million. Most of this money freed up the lent-out bond holdings of Easterside fund, thus allowing Yamada and Mori to redeem 3.2 billion yen.

This represented the last of the investment losses they had hidden away. The final step was to book goodwill from the Gyrus deal and to amortize that goodwill over ten to twenty years. Again, KPMG questioned the excessive M\&A advisory fees paid out. (Bacani, 2011) Yamada and Mori waited until KPMG was replaced in 2009 by Ernst \& Young before buying back the preference shares. Ernst \& Young, in turn, allowed US $\$ 177$ million to be booked as goodwill on the Gyrus acquisition.

In 2007, Olympus appointed British CEO, Michael C. Woodford. He immediately began questioning these transactions - specifically, the exorbitant M\&A advisory fees. Woodford was fired by Olympus two weeks later after talking to management in an attempt to rectify the discrepancies with the books. Woodford then went forward to British authorities as a whistleblower.

In 2011, after years of investigation, Olympus was forced to create an independent committee; whose findings were made public on December 6, 2011. A six-man committee, headed by a former Supreme Court judge, was appointed to investigate the Olympus scandal. Olympus survived the prospect of being delisted from the Tokyo Stock Exchange (TSE). The TSE removed the company from its watch list for automatic ejection from the world's second-largest bourse. It filed five years' worth of corrected statements, plus overdue first-half results, just hours before a deadline set by the TSE. (Japan Times, 2012)

Shuichi Takayama assumed office as President and CEO of Olympus after Shimoyama stepped down in November of 2011. In total, Takayama created three committees to look into the panel's findings: a management reform committee, a committee formed of attorneys that would investigate the liability of the board directors, and another committee made up of external lawyers that would study the liability of the non-directors and the corporate auditors. Olympus set January 8, 2012 as the due date for filing lawsuits against directors, and January 17, 2012 for other persons, including audit firms.

As of 2012, Olympus is suing its current president and 18 other past and present company officials over the scandal, seeking up to 3.6 billion yen in compensation for the accounting scam. Olympus said that all board members subject to the lawsuit would quit at an emergency shareholder's meeting to be held in March/April of 2012. On January 20, 2012, the Tokyo Stock Exchange decided to let Olympus stay listed after paying a small fine of 10 million yen or US $\$ 130,000$. (Japan Times, 2012)

In February 2012, Japanese prosecutors arrested and formally charged Olympus' former chairman, Tsuyoshi Kikukawa, two other former executives, Hisashi Mori and Hideo Yamada, and three men from consulting companies who allegedly collaborated in the scandal, with criminal charges. Prosecutors started a fresh investigation over alleged falsification from 2008 to 2010 . These six men faced up to 10 years jail time or US $\$ 125,000$ fine. The Nikkei Newspaper also reported that Olympus was fined \$1.2 million for false accounting. (Gallagher, 2012)

Japanese, U.S. and British officials are still investigating the case. 
The stock price fell from a high of 2,769 yen on July 22, 2011 to a low of 460 yen by November 11, 2011. As of July 6, 2011, Olympus shares traded at 1,291 yen. (Tokyo Stock Exchange, 2012) As of this writing March 3, 2014, the stock had recovered to 3,425 yen. (Tokyo Stock Exchange, 2012)

\section{TEACHERS NOTES: OVERVIEW OF CASE}

This case study is suited to financial accounting classes as an ethics exercise.

First, top management was able to hide $\$ 1.7$ billion in investment losses for nearly 20 years while external auditors lacked due diligence and failed to uncover all the falsified business transactions.

Olympus' top management continued to pursue failed investments that resulted in major losses. The company was initially able to hide these losses by booking the assets at historical cost versus fair market value. When accounting regulations changed, it forced them to book their assets at fair market value. As a result, Olympus created off-balance sheet entities to hide these losses. In a final attempt to complete this scheme, Olympus purchased Gyrus and booked the investment losses as goodwill.

Second, the whistle blower was Olympus' own President and CEO, Michael C. Woodford. He was from Great Britain, and had been employed by the company for more than a decade in Olympus' Europe division. He was an outsider that began to question the large, questionable M\&A fees. He was fired two weeks after attempting to address this issue.

Third, Woodford's charges gained credibility and the truth began to surface. Five months after the scandal broke in July 2011, Olympus stock was trading at a mere $16 \%$ of its former high. The company faced a potential delisting of shares from the Tokyo Exchange.

The firm was not delisted but paid a small fine of US $\$ 130,000$. Olympus sued the President and 18 other officials. The Board resigned in April 2012. Japan prosecuted the Olympus Chairman Kikukawa, Mori, and Yamada as well as three consultants. (Times, 2012) Perhaps the Economist summed this up best with the comment:

This is not an accounting misdeed-it is a mindset. Olympus, and the response of Japanese officialdom, is less about a single, sad incident as it is a view about the malleability of rules, and the subjectivity of their enforcement. Until Japan's institutions of governance-those internal to the corporations, as well as external regulators and prosecutors change, Japan cannot change. (Banyan, 2012)

\section{Discussion Questions}

1. Identify all stakeholders involved in the fraud and determine the issue at hand.

2. Japan has been noted for its 'lost decade.' As the decade of the 1990s stretches past year 2000 and then 2011, is there a cultural reluctance to face up to problems in Japan?

3. What message did Olympus Board transmit in firing their chosen CEO who became a whistleblower?

4. Link the actions of Olympus executives to Kohlberg's Six Stages of Moral Development.

5. Identify how the actions of Olympus Executives fit into the Rest/Kohlberg model of Moral Development.

6. What type of safety nets can be put in place to prevent or cut short accounting frauds such as this case?

7. Does the lack of uniform accounting standards encourage bad behavior? The United States had still not adopted International Financial Reporting Standards IFRS. Does the existence of IFRS for some and PCAOB GAAP for others simply make the regulatory environment more confusing allowing ducking and dodging of rules?

8. Olympus committed a crime, but in punishment they were permitted to stay enlisted on the Tokyo Stock Exchange while only receiving a small fine. How does this punishment for a white-collar crime look to the public? Does this diminish respect for ethical accounting standards? State your opinion. 


\section{Teaching Notes - Discussion Questions Answers 1-7:}

1. Key Players:

a. Toshiro Shimoyama. The longstanding President that may found to be less culpable than the others involved.

b. Hideo Yamada and Hisashi Mori. They were part of the masterminds behind the fraudulent schemes.

c. Michael Woodford. The new CEO who became the "whistleblower."

d. Shuichi Takayama. Assumed the presidency and all that came with it after Shimoyama left.

e. Shareholders of the company

f. Dealers in Olympus equipment world-wide.

g. Customers and owners of Olympus products who wondered if their investments would become worthless if Olympus broke up or was sold piecemeal to competitors.

Issue at hand: What ethical standards should be used to analyze this case and what is the proper application of these standards?

2. Academic studies indicate weak corporate governance and regulatory forbearance as two factors in prolonging the crisis in Japan. (Silver-Greenberg, 2012) Students should be made aware that the Olympus case is a microcosm that mirrors Japan's fall from grace at its stock market high of 1989. At that time there was worry that Japan might literally buy the United States. Its advance on multiple fronts of manufacturing and service appeared unstoppable. But since then, Korea and China have emerged as new major players on the scene. The inability or unwillingness to take a loss and clear the decks has resulted in an extensive period of stagnation in Japan. Students should note that the value of shares on the Tokyo Nikkei peaked at around 37,500 in 1989. Today, while other exchanges have gone up and down, the Nikkei has sunk to 9,020 as of July 2012. (Tokyo Stock Exchange, 2012)

3. The Model developed by Kohlberg features Three Levels and Two Stages for each level. An individual is seen as advancing in ethical awareness to each higher level or stage. Level One Stage Two exhibits a selfinterest orientation. Olympus Executives Hideo Yamada and Hisashi Mori operated at this base level by continuing to perpetuate the notion that nothing was wrong. The cover-up resulted in the necessity of hiding ever larger losses. Like many such scandals, by the time the truth came out it was much worse than if the original loss had been reported.

At Level Two, Stage Four the executives operate on an authority and social-order orientation. The same culture that was reluctant to report bank losses now transferred that thinking into the Corporate Headquarters. A social norm was maintained to make it appear that the company was operating without unusual problems.

Olympus executives failed completely at Level Three, Stage Five. At this points behavior should reflect the concept of a social contract. But Olympus chose the lower stages of self-interest rather than regard a higher calling to individuals beyond its immediate Corporate Culture. The resulting disaster nearly took the company down. (Crain, 16985)

4. Rest identified the Defining Issues Test (DIT) as well as the Four Component Model of Moral Development. Students should recognize that the cover-up of the losses was indeed a Defining Issue Test for Olympus. The executives failed this test in a way that disgraced an otherwise well performing company. The reluctance to 'come clean' about these issues when questioned by the new CEO paints an unfavorable picture of corporate governance.

It might be a good idea to have the class review this quote from the Bacani article: 
And yet the finance men and other executives involved do not appear to have financially profited from the fraud, if you discount the promotions and high ranks they achieved. They apparently did it out of personal pride, a misguided concern for the company's reputation, and fear of reprisal in a corporate culture where, as the panel puts it, "one had to be prepared to be kicked out of the company in order to make objection even if it was the right thing to do. (Bacani, 2011)

The four components of moral development are moral sensitivity, moral judgment, moral motivation, and moral character. Olympus executives proved insensitive to a moral responsibility to their stakeholders. The many years of refusal to admit to wrongdoing and report losses shows a lack of moral development. Olympus' top management displayed a lack of moral judgment. Like most cover-ups, they believed the truth would never come out. But like most cover-ups, it did. While the enormity of the losses by then was indeed serious, the failure to realize what would happen, even to the point of firing the whistle blower, Michael Woodford, displays an incredible lack of judgment. The motivation was simply to protect the guilty to the disadvantage of all the shareholders, dealers, and customers. That selfish motivation displays a total lack of character. The willingness to 'do the right thing' is the ultimate standard of character.

Students might be asked for examples in movies and novels of those that did the right thing. Tom Cruise character in Jerry McGuire insists that the company look out for the careers of its clients. His character loses his job but did the right thing. The point is that the executives at Olympus consistently did the wrong thing, even after Woodford pointed it out. Indeed, the company did not do the right think until forced to do so in the court of public opinion and resulting regulatory furor. (Myyry, 2003)

5. In the wake of the Enron and Worldcom scandals, Congress passed the Sarbanes Oxley Act. This created the Public Company Accounting Oversight Board PCAOB and took accounting regulation out of the hands of Certified Public Accountants. Since then the financial meltdown of 2008 occurred with firms needing rescues or bailouts from the government. As a result, another set of rules was passed, the Dodd-Frank reforms. Yet since then JP Morgan reported a US \$2 billion derivative loss. (Silver-Greenberg, 2012) Barclays Bank CEO resigned over an interest rate fixing scandal involving the London Interbank Overseas Rate. (Choudhury, 2012) Amid such world-wide scandals and the apparent inability to regulate such activity, students should be asked if regulation of behavior is possible. It appears that this will be difficult at best.

How can government regulate judgment? In this country, the move to greater scandal was preceded by the bailout of Long Term Capital Management. The unintended consequence of this action by Greenspan's FED was to send a 'Too Big to Fail' message to such funds and banks contemplating risky investments. (Dowd, 1999) Students should be asked to identify recent scandals that seem to be happening in spite of extensive attempts at regulation. The LIBOR scandal involving Barclays and the Derivative Loss at J P Morgan are two such recent examples.

6. Students should be asked about the apparent foot dragging in the United States about adopting IFRS. The change to market rules in Japan hastened the need for Olympus to become even more creative in the way it attempted to dodge responsibility. (The Accountant, 2012) A recent search at the time of writing reveals little since 2012 on this topic. It appears the US is more likely to develop standards in tandem with the IFRS.

7. The public may perceive the fine imposed on Olympus as a "slap on the wrist" but much of the public does not bother to weigh the effects of further sanctions. If Olympus was further sanctioned it could affect the company's viability, and potentially the livelihoods of its honest employees. Further sanctions could also place hardship on people who were not involved or even aware of the fraudulent actions of their superiors. Also, if some of the funds used came from employee stock options or benefit accounts, cutting Olympus out of the market would only bring further injustice to those shareholders. Students might be asked to obtain sentencing guidelines for both State and Federal crimes. If the Olympus executives had robbed a local store for several thousand dollars, would it be allowed to get off with a small fine? Or would its executives likely face mandatory jail time? In this country, Bernard Ebbers was sentenced to 25 years in 
prison for falsifying financial reports to cover a US \$1.7B loss. What punishment would fit the crime for Olympus executives? There is no right answer, of course, but this should stimulate a lively discussion among students. A final question might be: does the lack of potential jail time encourage such bad behavior? (Sentencing Guidelines, 2012)

8. The Olympus Imaging Case received world wide publicity including numerous articles in the Wall Street Journal and other financial publications. Students should be asked to locate such articles and report on their findings. Student responses should include their findings from not only US Publications but Japanese publications as well. Japan has been noted for its 'Lost Decade.' How has the reluctance to face up to problems potentially lengthened the time for Japan to recover its footing? It might be relevant for the students to trace the number of resignations and at which levels since the scandal began. Notably in the US Frank Dodd has required more transparent governance for publicly held corporations. Among other requirements, companies must now have a written policy on how they respond to whistle blowers.

\section{AUTHOR INFORMATION}

Dennis Elam PhD CPA, is an Associate Professor of Accounting at Texas A \& M University San Antonio. He earned his BBA, MBA, and Phd at the University of Texas at Austin. His blog professelam@typepad.com has garnered two national awards for accounting excellence. He makes his home in San Antonio with wife Christy and Jingles, a munchkin cat, and Bentley, a rescue Catahoula.

Marion Madrigal de Barrera earned a BBA in Accounting from Texas A \& M International University. She completed a Master of Science in Information Systems at the same institution in 2006. She attended Shepard Broad Law Center earning hours towards a Juris Doctor. She completed qualifying hours at Texas A \& M University San Antonio to sit for the Texas CPA Exam.

Maura Brook Jackson graduated from the University of Texas at San Antonio with a Bachelor's degree in Business Administration in Accounting in 2006. She earned a Master's of Professional Accountancy from Texas A\&M University at San Antonio in 2010. Maura is currently employed as an Auditor for a CPA firm in Houston, Texas. She has worked in taxation and auditing, though her true interests lie in Forensic Accounting where she has taken special studies on the topic. She is currently studying for the CPA Examination.

\section{REFERENCES}

1. Bacani, Cesar, The Olympus Scandal: When a Foreign CEO Rebels, Questex, 24 October 2011. http://www.cfoinnovation.com/content/olympus-scandal-when-foreign-ceorebels?page $=0 \% 2 \mathrm{C} 2 \& u t m \_$source $=$lyris $\&$ _medium=newsletter\&utm_campaign=cfo_weekly\&section=features

2. $\quad$ Bacani, Cesar, The Olympus Scandal: Now It All Makes Sense, Questex, CFO Innovation http://www.cfoinnovatoin.com/pint/4068

3. Banyan, Arrested Development, The Economist, March 6, 2012

4. Choudhury, Ambereen and Vaughan, Liam, Diamond Quits as Pressure Mounts on Barclays, July 3, 2012 http://www.bloomberg.com/news/2012-07-03/barclays-ceo-diamond-quits-after-record-libor-rigging-fine1-.html

5. Crain, W. C., Chapter Seven, Kohlberg's Stages of Moral Development, Theories of Development. Prentice-Hall. pp. 118-136, http://faculty.plts.edu/gpence/html/kohlberg.htm

6. Gallagher, Chris, Negishi, Mayumi, Japan Prosecutors Charge Key Figures in Olympus Scandal, Reuters, March 7, 2012. http://www.reuters.com/article/2012/03/07/us-olympus-idUSTRE8260C920120307

7. Kanaya, Akihiro and Woo, David, The Japanese Banking Crisis of the 1990s: Sources and Lessons, International Monetary Fund, Monetary and Exchange Affairs Department, January, 2000, http://www.imf.org/external/pubs/ft/wp/2000/wp0007.pdf

8. Kevin Dowd, Too Big to Fail?: Long-Term Capital Management and the Federal Reserve, Briefing Paper Number 52, September 23, 1999, http://www.cato.org/pubs/briefs/bp-052es.html 
9. Kubota, took, and Sieg, Linda, Olympus Sues Execs over S, Scandal, Shares Surge, Reuters, January 10, 2012. http://www.reuters.com/article/2012/01/10/olympus-idUSL3E8CA2JE20120110

10. Mintz, Steven, Financial Statement Fraud at Olympus, Ethics Sage, January 6, 2012. http://www.ethicssage.com/2012/01/financial-statement-fraud-at-olympus.html

11. McKenna, Francine, The Olympus Fraud Dissected, Forbes, January 2, 2012. ohttp://www.forbes.com/sites/francinemckenna/2012/01/02/the-olypus-fraud-dissected/

12. Myyry, Lisa, Components of Morality, Academic Dissertation, University of Helsinki, November 24, 2003, http://faculty.plts.edu/gpence/html/kohlberg.htm

13. Olympus Stock Price courtesy of Tokyo Stock Exchange, http://quotes.wsj.com/JP/7733/interactive-chart

14. Osawa, Uro and Nagaki, Kana, Results Reveal Cash Crunch, The Wall Street Journal, December 15, 2011 http://online.wsj.com/news/articles/SB10001424052970203430404577097473230925372

15. Silver-Greenberg, Jessica \& JP Morgan Discloses \$2 Billion in Trading Losses, Dealbook, May 10, 2012 , The New York Times http://dealbook.nytimes.com/2012/05/10/jpmorgan-discloses-significant-losses-intrading-group/

16. Tabuchi, Hiroko, Olympus Is given Fine but Avoids Delisting, The new York Times,

17. January 2012. http://www.nytimes.com/2012/01/21/business/global/olympus-is-given-fine-but-avoidsdelisting.html? $\mathrm{r}=1$

18. The Japan Times, Olympus Survives TSE Delisting for Now, January 21, 2012, http://www.japantimes.co.jp/news/2012/01/21/business/olympus-survives-tse-delisting-for-now

19. The Accountant, US Will Not Be Pressured into Adopting IFRS, February 28, 2012 , http://www.theaccountant-online.com/news/us-will-not-be-pressured-into-adopting-ifrs

20. US Sentencing Guidelines, FBOP Sentencing Table, USSG FBOP Sentencing Guidelines Chart, http://www.jailguide.com/federalsentencingchart.php 